\title{
EDITORIAL \\ LOS HUMANISTAS Y CIENTÍFICOS SOCIALES LEVANTAMOS LA MANO
}

\author{
William Andrés Martínez Dueñas \\ Editor
}

Este número de la revista Jangwa Pana emerge en medio del debate colombiano sobre la relevancia de las ciencias sociales en las agendas públicas de ciencia y tecnología. A partir de las convocatorias para la financiación de proyectos y estudios de doctorado lanzadas por el Departamento Administrativo de Ciencia, Tecnología e Innovación (COLCIENCIAS) de los últimos años se puede evidenciar que las ciencias sociales y las humanidades como áreas autónomas de investigación son cada vez menos relevantes para el Estado Colombiano. Al respecto las decanas y los decanos de las Facultades de Humanidades y Ciencias Sociales de universidades públicas de Colombia han declarado que:

"Nos preocupa la desfinanciación de la investigación por parte de COLCIENCIAS en todos los saberes, pero de manera especial en las humanidades y las ciencias sociales, que ha sido una constante, pero que en los últimos años se ha agudizado." (ver declaración de la Asociación de Facultades de Humanidades y Ciencias Sociales, 2015).

A pesar de esto, con este número y los anteriores de la revista Jangwa Pana, hacemos evidente la relevancia de las Humanidades y las Ciencias Sociales, ya que entre los resultados de investigación y reflexiones tratados por los humanistas y científicos sociales reunidos en este número se encuentran temas tan relevantes para nuestras sociedades como: identidad nacional, imagen corporal, género y poder, calidad educativa, conflicto, justicia y paz, prácticas culturales urbanas, neologismos en el lenguaje de señas, recreación, literatura y cine latinoamericano. A través de estas temáticas los autores abordan problemáticas de gran importancia no solo disciplinar, sino también de pertinencia social como el conflicto armado y las crisis políticas contemporáneas. Con esto los antropólogos, sociólogos, filósofos, lingüistas y críticos literarios, por mencionar algunas de las ramas de las humanidades y las ciencias sociales, levantamos la mano y presentamos nuestro aporte y reflexión a las diversas preocupaciones que atañen a nuestras sociedades.

Por otro lado, nos complace mucho anunciar que la revista ha sido indexada en el Índice 
Bibliográfico Nacional - Publindex de Colombia, lo cual evidencia la calidad y relevancia de sus publicaciones y del proceso editorial. Este reconocimiento es el resultado del proceso colaborativo y constante desde el año 2001 por parte de los miembros del Programa de Antropología de la Facultad de Humanidades de la Universidad del Magdalena, así como de colegas de diferentes universidades de Colombia y el mundo, lo cual ha permitido difundir la producción desde las ciencias sociales y las humanidades, sin descuidar la complementariedad con otras áreas del saber. Creemos que ahora más que nunca el papel de divulgar en estas áreas del conocimiento es de gran relevancia no solo para entender las crisis sociales, ambientales y económicas contemporáneas, sino también para permitir reflexiones que proyecten soluciones a dichas crisis.

Finalmente expresamos nuestro agradecimiento a los autores, evaluadores, al comité editorial, al comité científico, a la Vicerrectoría de Investigación de la Universidad del Magdalena y a Usted estimado lector, por el apoyo brindado para poder continuar con este proyecto por más de una década. 